\title{
Ability Emotional Intelligence and Children's Behaviour in the Playground
}

DOI:

10.1111/sode. 12340

\section{Document Version}

Accepted author manuscript

Link to publication record in Manchester Research Explorer

\section{Citation for published version (APA):}

Qualter, P., Urquijo, I., Henzi, P., Barrett, L., \& Humphrey, N. (2018). Ability Emotional Intelligence and Children's Behaviour in the Playground. Social Development, 28(2), 430-448. https://doi.org/10.1111/sode.12340

\section{Published in:}

Social Development

\section{Citing this paper}

Please note that where the full-text provided on Manchester Research Explorer is the Author Accepted Manuscript or Proof version this may differ from the final Published version. If citing, it is advised that you check and use the publisher's definitive version.

\section{General rights}

Copyright and moral rights for the publications made accessible in the Research Explorer are retained by the authors and/or other copyright owners and it is a condition of accessing publications that users recognise and abide by the legal requirements associated with these rights.

\section{Takedown policy}

If you believe that this document breaches copyright please refer to the University of Manchester's Takedown Procedures [http://man.ac.uk/04Y6Bo] or contact uml.scholarlycommunications@manchester.ac.uk providing relevant details, so we can investigate your claim.

\section{OPEN ACCESS}


Ability Emotional Intelligence and Children's Behaviour in the Playground Running Head: EMOTIONAL INTELLIGENCE AND SOCIAL BEHAVIOUR

Pamela Qualter $^{1 *}$, Itziar Urquijo ${ }^{2}$, Peter Henzi ${ }^{3}$, Louise Barrett $^{3}$, and Neil Humphrey ${ }^{1}$

1. Manchester Institute of Education, University of Manchester, UK

2. Faculty of Psychology and Education, University of Deusto, Spain

3. Department of Psychology, University of Lethbridge, Lethbridge, Alberta, Canada

*Correspondence concerning this article should be addressed to Pamela Qualter,

Manchester Institute of Education, University of Manchester, Oxford Road,

Manchester, UK. Contact: pamela.qualter@manchester.ac.uk

Conflict of Interest Statement: The authors whose names are listed above certify that they have no affiliations with or involvement in any organization or entity with any financial or non-financial interest in the subject matter or materials discussed in this manuscript.

Acknowledgements: The research was supported in part by a grant from the Economic and Social Research Council (Grant RES-000-22-1802) awarded to the first, third, and fourth authors. 


\begin{abstract}
We explored whether emotion understanding promotes positive social functioning in childhood using the Ability Emotional intelligence (AEI) framework, which defines emotion understanding more broadly than is common in developmental science. The prospective study included children ages 9 to 11 years who completed a measure of AEI at the start of the school year, and whose playground interactions were observed for one full year. Findings showed that, among girls, low AEI was associated with higher levels of direct aggressive behaviour on the playground; boys and girls high or low in AEI were more likely than their peers to watch others during playground social interactions. Further, higher AEI was associated with indirect aggression in school, suggesting higher AEI during childhood may be associated with the developmental transition from direct to indirect forms of aggression. The implications of the findings for school practice in relation to the teaching of emotion understanding are discussed.
\end{abstract}




\section{Ability Emotional Intelligence and Children's Behaviour on the Playground}

Social engagement with peers is central to the lives of children in school. But, children differ in their emotion-related abilities, which affects how they communicate and engage with others. How those skills affect social processes during childhood has been examined using different measures of emotion understanding (Trentacosta \& Fine, 2010). However, measures of emotion understanding during childhood are limited because they focus on the skills of labelling emotion expression and attribution of emotions to prototypical situations; they rarely include consideration of emotional complexity that we see in adult models of emotion understanding (Castro, Cheng, Halberstadt, \& Grühn, 2016). That limitation is despite broad conceptualization of children's emotional competence (Saarni, 1999). Such a limited focus constrains our understanding of emotion understanding and how it impacts outcomes.

The Ability Emotional Intelligence (AEI) framework explicitly defines the skill sets that comprise emotion understanding, and fits well with Saarni's conceptualization of children's emotional competence (Saarni, 1999, 2007) and the EUReKA model of emotion understanding (Castro, Cheng et al., 2016) that attempts to integrate definitions of emotion understanding across the lifespan. Although the AEI system is seen as an adult model of emotion understanding, it has been applied successfully to youth. It offers a more inclusive assessment of emotion understanding than approaches focused only on one broad ability representing the construct of emotion understanding (Castro, Cheng et al., 2016). The AEI framework includes different skill sets of emotion recognition (awareness and labelling of prototypical emotions) and emotion knowledge (internal and external causes, consequences and functions of emotions, and management of emotions). It, thus, provides a way to understand how emotion understanding, defined in a much 
broader way than is common in developmental science, affects social processes during childhood.

\section{Ability Emotional Intelligence and Social Behaviour}

Ability Emotional Intelligence (AEI) involves being able to (1) perceive accurately, appraise, and express emotion, (2) use emotions to solve problems, (3) understand emotional language to reflect on how emotions combine, and (4) regulate emotions to promote emotional and intellectual growth (Mayer, Caruso, \& Salovey, 2016; Mayer \& Salovey, 1997; Salovey \& Mayer, 1990). Those abilities form a hierarchy, increasing in complexity from emotion perception to emotion management across development. A person's overall AEI, then, is a measure of their emotional capabilities (Brackett, Rivers, Shiffman, Lerner, \& Salovey, 2006). The model fits well with the idea that emotion understanding is "expertise in the meaning of emotion" (Castro, Cheng et al., 2016, p. 259), and models of emotion understanding that link emotion understanding with cognitive development (Saarni, 1999). The AEI perspective contrasts with Trait Emotional Intelligence (TEI), which is considered to be an aspect of personality (Petrides, Pita \& Kokkinaki, 2007). In the current paper, we only examine social functioning and AEI because the definition of emotion understanding encompassed within the AEI framework maps well onto the EUReKA model of emotion understanding (Castro, Cheng et al., 2016) that discusses multiple skill sets; we did not examine how TEI and emotion self-efficacies influence social processes.

Using the AEI framework (Mayer et al., 2016) we hypothesized that someone low in AEI would have problems in one or more of the following areas: (1) accurately perceiving others' emotions, whilst also monitoring their own, (2) using their own and other people's feelings to direct behaviour and thought, and (3) regulating their own and 
others' emotions to promote discussion. Such a complex organizational framework of emotion understanding skills fits well with current ideas that emotion understanding should be assessed as a broad construct during middle and late childhood (Castro, Halberstadt, \& Garrett-Peters, 2016).

Saarni (1999) asserted that emotion understanding develops within social contexts. This idea is consistent with AEI theory, where it is argued people must be able to perceive emotions and how they are linked to behaviour within current social situations and have a detailed understanding of which behavioural response they should use, based on their appraisal of their own and other people's emotions. Also, they must engage in the more complicated procedure of using their responses flexibly, using on-going emotional feedback from the social context to inform those decisions. Lopes, Mestre, Guill, Kremenitzer, \& Salovey, (2012) noted how someone might make mistakes during that process: "when people are angry, they might do or say things that harm relationships with others, without due consideration of alternative solutions and possible consequences" (p. 712). Based on AEI theory and current conceptualisations of emotion understanding, we would expect people higher in AEI to make fewer of those mistakes because they understand how their feelings, and actions that come from those feelings, impact others. In the current study we examined that idea explicitly by observing the interactions of children to determine how their AEI impacted social engagement during recess. We investigated whether those with higher AEI were as skilled in social functioning as we would predict from current conceptualizations of emotion understanding.

A meta-analysis showed that emotion understanding correlated consistently with social outcomes during childhood and adolescence (Trentacosta \& Fine, 2011). When 
emotion understanding is assessed more broadly using AEI assessment, it is also strongly related to self-report measures of social adjustment in older adolescents and adults. Research shows that lower AEI is related to self-reported use of aggressive behaviour (García-Sancho, Salguero, \& Fernández-Berrocal, 2016), whereas higher AEI is associated with prosocial behaviour (Charbonneau \& Nicol, 2002; Ciarrochi, Chan, \& Baigar, 2001; Ciarrochi, Chan, \& Caputi, 2000; Lopes et al., 2004, 2005). Among older adolescents and adults, AEI also is positively correlated with self-reported social network size and quality of group and friendship interaction (Brackett, Mayer, \& Warner, 2004; Lopes et al., 2004), including those with the opposite sex (Lopes et al., 2004). Such findings support Saarni's (1999) idea that understanding one's own thoughts and emotions facilitates an understanding of others' thoughts and feelings, which increases the likelihood of successful social interactions.

\section{The Reliance on Self- and Other-Reports of Social Behaviour}

Some studies exploring the link between children's emotion understanding and social behaviour used observational assessment of peer engagement (Trentacosta \& Fine, 2010). Most studies examining middle and late childhood, however, rely on teacher and peer reports of social proficiency. Findings using the AEI framework, linking emotion understanding to social behaviour, are based on self-reports of peer interactions. For children and adolescents, teacher reports have most often been used to evaluate both AEI and behavioural characteristics such as co-operation, disruptive behaviour, shyness, aggressiveness, dependence, leadership, and intimidation. However, both self-and informant-reports have problems: they are predisposed to social desirability response biases (MacNeil \& Holden, 2006; Marlow \& Crowne, 1961; Van de Mortel, 2008), providing only subjective accounts of social proficiency. Because of such problems, it is 
preferable to capture social competence by measuring actual real-time social behaviour (Hubbard et al., 2002). The use of observational research designs allows the researcher to obtain a more objective picture of social relationships in natural settings (Berg \& Lune, 2004). To our knowledge, the observational approach, although it has been used to examine the impact of emotion understanding on social relationships during middle and late childhood, has only been used once before in relation to AEI (Brackett et al., 2006, Study 3). In that study, observational methods were used to examine whether AEI could predict observable behaviour during an encounter between young adults and an ostensible stranger in a getting-acquainted session. Findings showed that AEI predicted social behaviour, but only for men. In the current study, we used observational methods to examine whether AEI predicted children's engagement with peers on the playground. We observed their behaviour over the course of one full school year, using continuous time sampling to code playground behaviour once every week.

\section{Controlling for Verbal Ability}

Understanding emotions requires a certain level of language proficiency. For example, we need to use language when examining the emotional context of situations (Mayer \& Salovey, 1993) and when we consider the behavioural intentions and emotional responses of others (Beck, Kumschick, Eid, \& Klann-Delius, 2012). Early language development is also related to later emotional development and behaviour (Clegg, Law, Rush, Peters, \& Roulstone, 2015). Thus, language ability was controlled in the current study.

Examination of a Quadratic Relation between Ability Emotional Intelligence and

\section{Social Behaviour}


So far, empirical examination of whether emotion understanding, and AEI specifically, is associated with social functioning has mostly assumed a linear association. However, there is evidence of quadratic associations, suggesting those who have very high AEI or very low AEI may be qualitatively different in outcome measures compared to those who score in the mid-range. For example, child sexual abuse was strongly predictive of suicidal ideation and attempts among those with low AEI, weakly predictive among those with medium EI, and completely unrelated among those with high EI (Cha \& Nock, 2009). Other researchers propose a threshold of EI, above which levels are more likely to predict successful outcome (Brackett et al., 2004; Davis \& Humphrey 2012; Qualter, Whiteley, Hutchinson, \& Pope, 2007). Emotion understanding skills may also confer some disadvantages during middle and late childhood: when a child knows too much about what others are feeling or is overly sensitive to emotion information, they may become distracted, which interferes with their ability to behave appropriately (Hoglund, Lalonde, \& Leadbeater, 2008). Guided by those findings, we propose there may be a minimum level of AEI that is necessary for successful social engagement in childhood, or there may be disadvantages to having low or high AEI compared to scoring in the mid-range of AEI scores.

\section{Aims of the Study}

The current study examined whether emotion understanding, measured using a broad assessment of emotion understanding within the AEI framework, was associated with observed social behaviour on the playground over a school year. Verbal language ability was controlled for in our analyses. Based on previous work on emotion understanding within the developmental sciences and within social psychology on AEI, we expected that children's AEI would be (a) positively associated with prosocial behaviour, (b) negatively associated with negative peer interaction, including direct 
aggression, distress, and peer rejection, and (c) negatively associated with nonengagement with peers during recess. Analyses examined (1) gender differences in those associations, and (2) quadratic and linear relationships.

\section{Method}

\section{Participants}

Seventy-eight children (33 females, 45 males) from the Lancashire Longitudinal Study of Social and Emotional Development (LLSSED) took part in this study. The children in LLSSED came from eight representative schools located in the North West of England determined by the government Index of Multiple Deprivation and were between 6 and 11 years of age $(\mathrm{M}=8$ years, 1 month, $\mathrm{SD}=20$ months; $56.7 \%$ males $)$ at the start of that study. Children taking part in the current observational study were on average 10 years and 2 months (SD $=7$ months; 55.13\% male) when they completed the emotion understanding measure at the start of the year and were observed for the academic year following that. Children from ethnic minorities represented $8 \%$ of the total group in the current study, comprising $1.33 \%$ from Central or South-Eastern Europe (Hungary, Poland, Turkey and Romania) and the remainder from areas of Southern Asia, including Bangladesh, India and Pakistan. Parents reported that most children had been born in the UK $(98.67 \%)$. Those percentages were comparable to those in the larger LLSSED sample where $4.70 \%$ of children came from ethnic minority groups and $97.86 \%$ were born in the UK, and similar to the national picture of state funded primary schools (Department for Education, 2012). The number of children in the current study $(\mathrm{N}=13.3 \%)$ and LLSSED (12.4\%) who were identified as having special educational needs (SEN) was slightly lower than the national averages (Department for Education, 2013). Deprivation levels in the current sample, measured by eligibility for free school meals (current sample: 29.33\%; 
LLSSED: 24.36\%), were somewhat higher than national levels (Department for Communities and Local Government, 2015; Department for Education, 2012). Please note that parents of three children did not provide demographic information for their children.

Of those parents contacted to ask for permission to work with their children as part of LLSSED, 68.79\% agreed, which meant 186 parents revoked participation. Those parents who revoked participation noted that they did not want their children to be recorded during peer interactions. Children who were over 9 years in the LLSSED were included in the current study because they were old enough to complete the Ability Emotional Intelligence measure.

\section{Measures}

Ability Emotional Intelligence (AEI). Mayer-Salovey-Caruso Emotional Intelligence Test-Youth Version (MSCEIT-Yv; Mayer, Salovey, \& Caruso, 2005) was used. The scale consists of 101 items (of which 97 are scored) that measure different aspects of AEI: 1) Perceiving emotions - individuals identify emotions in photographed facial expressions, 2) Facilitating emotions - participants rank, using a standardized scale, the extent to which different emotions impact behaviour and decision making, 3) Understanding emotions - includes vignettes and requires participants to select the answer representing what emotion a protagonist is feeling, 4) Managing emotions - participants read several scenarios and pick, from several options, the best solution for managing emotions in each scenario. Multi-Health Systems, the test distributor, using expert norms, scored the data, providing means for each branch of the MSCEIT-YV, and a total MSCEIT-Yv score. Internal consistency scores of the MSCEIT-Yv for the four branches, ranged from $a=.67$ [Branch 1: perceiving emotion] to .86 [Branch 3: understanding emotions]; for the overall measure, $a=.91$. Given the high correlations between the 
overall and subscale scores in the current study (.60 [Section A] - .81 [Section D]), and the small sample size, analyses were restricted to ability EI as a global construct and total MSCEIT-Yv scores were used.

Verbal Ability. The British Picture Vocabulary Scale (BPVS: Dunn, Dunn, Whetton, \& Burley, 1997) is designed to measure children's receptive vocabulary for Standard English between the ages of 3 and 16 years. The BPVS is one of the most frequently used tests assessing verbal ability. It comprises 150 picture plates, each with four pictures, one plate for each word. The participant points to or gives the number of the picture most like the stimulus word, which is spoken by the investigator or shown on the printed card. Language ability in the current sample was within the normal range, with the standard mean being 101.46 (SD 14.67; range 67.00-134.00).

Observed Peer Interactions. Participants were videotaped without sound during recess. The video cameras were placed unobtrusively at vantage points from which the playground was visible (i.e., an adjacent classroom, lunch-hall). Camera operators utilized a table of numbers that represented participant IDs, the numbers having been picked at random from all participants in that school. Children identified by the numbers were videoed on that day and video operators were told to follow that child for as long as possible at that time; videoing stopped for that child when he/she was no longer visible and videoing of the next child on the table of random numbers began. Each target participant was observed in 39 recesses, which equated to once per week for the full school year; on average we had 18.21 hours of footage per child (range $=5.35$ to 34.38 hours; $\mathrm{SD}=6.76$ hours), which meant that each child on average was observed for 28.01 minutes each week $(\mathrm{SD}=10.40$; range $=8.23$ to 52.90$)$. If the child was away one week, two observations were collected the following week. All observations of a target participant were coded in Observer XT 9 (Noldus, Netherlands) by coders who were blind 
to the children's AEI scores. The sixteen undergraduate and post-graduate observers and the four faculty members were required to reach an acceptable level of inter-rater reliability with practice videotapes (ICCs >.80) before they were able to code data; assessments of reliability were conducted throughout the study to avoid observer drift problems (Pellegrini, 1996).

Within Observer XT, the data were coded across time using continuous time sampling. From those data, the frequencies of the categories of behaviour were calculated as a percentage of the total observed time as recommended by Altmann (1974). Reliability between observers was assessed using Intra-Class Correlations (ICC) across 5\% of the observations. Reliability was acceptable and exact details are noted below for each behavioural code used in the current study. Ninety-five percent of the interactions were same-gender, similar to previous studies using observational methodology (e.g., Blatchford et al., 2003).

Peer rejection. This construct was assessed by negatively received bids. Negatively received bids comprised the situation in which the target participant was alone, but initiated interaction that was rejected by the other peer(s) $(\mathrm{ICC}=0.95)$. Greater frequencies of this behaviour denoted higher peer rejection. The distribution of this behaviour was not skewed and was normal ( skewness $=1.17$, kurtosis $=.71)$.

Prosocial behaviour. This categorization included positive interaction and initiations made by the target child that led to positive interactions with other children. The category included instances when the target child participated in a conversation or in play that was accompanied by smiling and/or laughter $(\mathrm{ICC}=.86$ ). Rough and tumble play behaviour was considered to be a prosocial behaviour. In addition, we included instances when the target child was alone, but initiated an interaction with another person in a group or dyad, where the overture (a tap on the shoulder, speaking to the other person, or trying to get 
their attention another way) was accepted by the other child who brought the target child into the group or moved out of the group to join them $(\mathrm{ICC}=.78)$. The distribution of this behaviour was skewed and non-normal (skewness $=-1.40$, kurtosis $=4.14$ ). Because behavioural data were percentages between $0 \%$ and $100 \%$ of overall behaviour, data were subjected to an arcsine transformation that was successful in normalizing the distribution (skewness $=-.03$, kurtosis $=-1.45)$. These transformed data were used in the analyses. The raw mean for prosocial behaviour is shown in Table 1 in order to provide information regarding its prevalence in the peer interactions.

Non-engagement. Three categories of non-engagement were analysed: passive behaviour, playing alone, and being alone but watching peers. We classified the behaviour as passive when the target child was part of a group, but not interacting with its members, but watching them $(\mathrm{ICC}=.89)$; the child was noted as playing alone if they were on their own and engaged in play by themselves $(\mathrm{ICC}=.95)$; the child was classified as being alone but watching peers when s/he was not engaged in interaction with any peers, and was watching peers in play/interaction $($ ICC $=.97$ ). The distribution of data for passive behaviour was not skewed and was normal (skewness $=.724$, kurtosis $=-.18$ ); data for playing alone and being alone were non-normal (playing alone: skewness $=4.83$, kurtosis $=26.69$; being alone: skewness $=1.68$, kurtosis $=2.41$ ). Arcsine transformations normalized the distributions for being alone (skewness $=-0.60$, kurtosis $=-.420$ ) and playing alone (skewness $=-.83$, kurtosis $=1.67$ ). The raw means for these behaviours are shown in Table 1.

Negative peer interaction. There were three categories of negative interaction: direct aggression, social exclusion, and distress. Direct aggression was categorized as the target participant engaging in either verbal or physical aggression toward a peer $($ ICC $=.81)$. Indirect aggression was categorized as the target participant deliberately ignoring another 
person's attempt at interaction $(\mathrm{ICC}=.76)$. Distress was categorized as the target participant crying or showing emotional upset $(\mathrm{ICC}=.78)$. The distributions of these behaviours were skewed and non-normal (skewness for direct aggression, indirect aggression, and distress was 2.52, 3.30, and 2.81 respectively; kurtosis for direct aggression, indirect aggression, and distress was 7.78, 11.15, 7.30 respectively). Arcsine transformations were successful in normalizing all distributions (skewness and kurtosis $=$ $.84, .83$ for direct aggression; -.36, 2.00 for indirect aggression; and -1.00, 1.54 for distress). Those transformed data were used in the analyses. The raw means for those behaviours are shown in Table 1.

\section{Results}

\section{Analysis Plan}

Our sample size for the subsample of the LLSSED did not permit the use of latent growth curve modeling techniques (LGCM) to examine how emotion understanding predicted changes in social behaviour (Duncan, Duncan, \& Strycker, 2006). However, LGCM of behavioural data for the whole cohort of LLSSED showed no changes in behaviour over time (Rotenberg et al., 2014). Thus, in the current study, we decided it was appropriate to average each behaviour across the observed sessions and use a series of regression analyses to examine whether emotion understanding and verbal ability predicted those behaviours. We explored whether there were both linear and quadratic effects of emotion understanding on the average amount of each behaviour. We looked at whether gender also influenced behaviour.

\section{Linear and Curvilinear Relations between Emotional Intelligence and Behavioural Variables}

Hierarchical Regression Analyses (HRAs) were carried out with the predictors on 
the following steps: (1) gender, verbal ability, and AEI, (2) AEI squared (Sq), (3) AEI x gender, and (4) AEI squared (Sq) x gender. The squared (Sq) in the HRAs was the AEI $\mathrm{x}$ AEI and served as a test for a quadratic relation (Cohen et al. 2003). Before analyses, the predictors were centred by subtracting their mean; gender was dummy coded $(0=$ female and $1=$ male). The HRAs were carried out for each behaviour separately. When two-way interactions between either AEI x gender or AEI squared $(\mathrm{Sq}) \mathrm{x}$ gender were found on a given dependent behavioural measure, they were examined further by testing for the linear and quadratic relations on the measure for each gender separately.

Results from the HRAs can be found in Tables 2 - 4. They revealed no significant effects of AEI on prosocial behaviour, playing alone, or distress. We found a two-way AEI x gender interaction for (1) alone but watching peers, and (2) passivity during social engagement. Those two-way AEI x gender interactions were qualified by AEI Squared $\mathrm{x}$ gender interactions, which are described below. We also found an AEI Squared x gender interaction for direct aggression and a main effect of AEI Squared for engagement in social exclusion.

Results for being alone but watching others, passivity during interaction, and direct aggression yielded a two-way AEI Squared x gender interaction that qualified any observed main effects and other interactions. Those interaction effects confirmed that there was a quadratic relation between AEI and behavioural outcome that differed by gender. Specifically, it was the case that boys scoring high or low in AEI were more likely to be alone, but watching others than their male peers who scored in the mid-range of scores for AEI (see Figure 1); girls scoring low in AEI were more likely to engage in direct aggression than their female peers scoring in the mid or higher range of AEI scores, (Figure 2), and girls high or low in AEI were more likely to be passive during interaction 
than their same-gender peers scoring in the mid-range of AEI (Figure 3). The HRAs also revealed a main effect of AEI Squared for engagement in the social exclusion of other children, with children in the mid-range or higher range of AEI engaged in more social exclusion than those low in AEI (see Figure 4).

We found gender effects for (1) alone but watching others and (2) passivity during interaction. Because those behaviours are similar and involve watching other people - one is when the target child is alone and one where the target child is with others - we examined whether there was a difference in the amount of overall interaction in which boys and girls engaged. Results supported that idea with girls engaged in more overall interaction $(\mathrm{M}=94.90, \mathrm{SD}=3.39)$ than boys $(\mathrm{M}=91.44, \mathrm{SD}=6.59 ; \mathrm{t}(69.10$, equal variance not assumed $)=3.02, \mathrm{p}=.004$.

\section{Discussion}

The current study examined whether broadly defined emotional understanding, examined within the Ability Emotional Intelligence (AEI) framework, was associated with children's observed social behaviour. Controlling for verbal language ability, we found that AEI measured at the beginning of the school year predicted social functioning on the playground across that school year. In line with previous studies that measured social behaviour using self- and informant-reports (Davis \& Humphrey, 2012; EsturgóDeu \& Sala-Roca, 2010; García-Sancho et al., 2016; Rivers et al., 2012), we found that low AEI was linked to higher levels of direct aggressive behaviour. However, we found that effect for girls only. In addition, we showed that higher AEI was associated with more engagement in social exclusion of classmates. Taken together, those findings suggest higher AEI during childhood is associated with the developmental transition from direct to indirect forms of aggression. Further, boys and girls high or low in AEI watched 
others when those peers were in social interaction. Boys were more likely to do that when they were alone, but for girls such behaviour occurred during interaction, which was simply because girls were engaged in interaction more than boys. AEI was not found to predict prosocial behaviour, at odds with our expectations and with previous research with adults and older adolescents (Charbonneau \& Nicol, 2002; Ciarrochi, Chan, \& Baigar, 2001; Ciarrochi, Chan, \& Caputi, 2000; Lopes et al., 2004, 2005). The current study extended earlier work on emotion understanding through the use of its broader assessment within the AEI framework, providing further support for the EUReKA model of emotion understanding (Castro, Cheng et al., 2016). In addition, our study extended the work on AEI and social behaviour in other important ways: (1) it used objective examination of social behaviour collecting data via robust observational methods, (2) examined effects separately for males and females, and (3) examined curvilinear effects.

We expected higher AEI to be associated with prosocial behaviour. That was not the case. Given that previous research with adults and older adolescents showed strong associations between higher AEI and prosocial behaviour (for review, see Mayer, Salovey, \& Caruso, 2008), our findings might reflect developmental changes in that relationship. Future research will want to examine that idea, exploring changing relationships across ontogeny.

The findings support the idea that there are developmental changes from direct to more indirect forms of aggression as children's social and emotional skills increase. In previous work, indirect aggression was seen to develop from around the age of three years, continuing to increase as children developed more sophisticated verbal and social skills (Crick et al., 2006; Crick, Ostrov, \& Kawabata, 2007), peaking during later childhood and adolescence (see Voulgaridou \& Kokkinos, 2015 for review). Our finding 
that one aspect of indirect aggression, engagement in social exclusion, was associated with higher AEI supports that earlier literature. In future work, researchers could measure emotion understanding using the comprehensive framework of AEI to explore its links to direct and indirect aggression over ontogeny; that future research should use robust longitudinal designs so that age-related associations between AEI and direct and indirect behaviour can be established.

Our findings showed that lower AEI was associated with the use of aggressive behaviour toward peers. But, there is a growing body of research supporting Saarni's (1999) claim that emotional self-efficacy is also important for understanding how emotion understanding is linked to behaviour. Indeed, children who overestimate or underestimate their social and emotional competence are more likely to be aggressive (David \& Kistner, 2000; Diamantopoulou, Rydell, \& Henricsson, 2008; Hughes, Cavell, \& Grossman, 1997; McQuade, Achufusi, Shoulberg, \& Murray-Close, 2014; Sandstrom \& Herlan, 2007), highlighting the need to look at the mismatch between AEI and emotional self-efficacy (ESE) in predicting behavioural outcomes. It has been argued elsewhere (Qualter et al., 2018) that simultaneous examination of AEI/ESE is advantageous because it reveals within-person discrepancies, which are linked with selfreported social relationship quality and poorer well-being outcomes in adults (Salguero, Extremera, Cabello, \& Fernández-Berrocal, 2015; Sheldon, Dunning, \& Ames, 2014). Although there is some evidence that high ESE can offset the negative effects of low AEI (Gohm, Corser, \& Dalsky, 2005; Salguero et al., 2015), such an examination in relation to child and adolescent social behaviour has yet to be done. Such work highlights the need to consider emotion self-efficacy and how it fits into the EUReKA model of emotion understanding (Castro, Cheng et al., 2016). 
Future work also should examine the full range of behaviour that constitutes indirect aggression. We examined explicit social exclusion observed on the playground, but indirect aggression also includes actions that may be less obvious, and much harder to detect via observational methods. Such behaviours include getting others to dislike a person, purposefully disclosing others' secrets to peers, and ridiculing the person using body and facial gestures (Vaillancourt, 2013). According to Björkqvist (1994), indirect aggression is less risky for the perpetrator because he/she often remains anonymous, reducing the likelihood of a counterattack, but the perpetrator has to be socially and emotionally skilled. Knowing that your target will be affected emotionally by certain actions is important for success using indirect aggression, as is knowing that you can use your emotional and social skills to claim there was no intention to harm if you get caught. Thus, descriptions of indirect aggression imply that higher levels of broad emotion understanding skills are required for the successful implementation of indirect aggression, and our findings supported that in relation to social exclusion. How emotion understanding broadly measured using AEI measurements is related to other forms of indirect aggression and how that relationship changes over ontogeny should be examined in future work.

We found that children high or low in AEI, compared to their peers in the midrange of AEI scores, spent more time watching others who were interacting. The exact reason for those effects is unknown, but it is likely that those children high or low in AEI are looking for ways in which to engage with peers. Current thinking about onlooker behaviour is that it is linked directly to emotional immaturity (Coplan, Gavinski-Molina, Lagacé-Séguin, \& Wichmann et al., 2001). Recent research provides support for that notion showing that poorer emotional understanding was related to more onlooker, unoccupied behaviour in boys (Veiga et al., 2017). Our work provides further support, 
confirming those prior research findings. Current thinking cannot explain why we found the same effects for those high in AEI. One possibility is that increased onlooker behaviour among children high in AEI is an attempt to surveil the social environment for verbal and non-verbal cues among other children that can then be used to guide subsequent social interactions to achieve a desired outcome. The next step, then, is to understand the cognitive processes during times when children are engaged in onlooker behaviour when they are alone or in groups. Future work will want to examine whether the same motivation is behind onlooker behaviour for those high or low in AEI: are both groups looking for ways to engage with others and are they looking at the same behaviour and gestures shown by their peers? Such work will advance our understanding of why high AEI is linked to onlooker behaviour, helping explain why higher emotion understanding is linked to better social and well-being outcomes. That work will inform interventions designed to increase emotion understanding, particularly those focused on increasing the full range of emotion understanding skills measured using AEI assessments.

\section{Limitations and Future Work}

Our comprehensive assessment of emotion understanding and our use of observation methodology to examine social processes longitudinally are strengths of the current study. However, the study also has limitations. First, the study included only children in late childhood so it is unclear whether the results reflect associations that are unique to that developmental period or are generalizable to other age groups. Replication of the study and exploration of the associations across youth will be important in future work. Second, given the associations between AEI and personality, with a meta-analysis reporting moderate correlations between AEI and Openness and Agreeableness (Roberts, 
Schulze, \& MacCann, 2008), future research should also consider controlling for personality/temperament characteristics.

Third, the EUReKA model (Castro, Cheng et al., 2016) includes, uniquely, three foci of emotional understanding applied to the self, specific others, and others in general, but the measurement of AEI used here focused only on the 'general' focus. That focus is important - and is the main focus in $88 \%$ of measures (Castor, Cheng et al., 2016) because it includes how people typically display emotions and how people typically react to different emotional situations. But, missing from the current exploration are the other two foci of emotion understanding - the self and the specific other - constraining our understanding of emotion understanding skills and the impact they have on social processes with peers in school. It is important to incorporate those other foci of emotion understanding into future analyses linking broader emotion understanding to peer social processes during childhood. If we do that, we will know more about the degree to which understanding of different foci are related to, and the degree to which they predict, different social relationships. That future work will have important implications for school-based interventions designed to increase emotion understanding skills, with the aim of increasing social competence.

Finally, although we set out to examine how the different skill sets that make up emotion understanding within the AEI framework differentially predicted social interaction, the small sample prohibited that examination. Failing to differentiate skill sets could be viewed as a limitation, although in other recent work (Castro, Halberstadt et al., 2016), the different skills of emotion understanding did not contribute unique effects. We encourage researchers to examine both the collective and unique effects of emotion understanding skills on social processes in future studies. 


\section{Implications of Findings for Interventions}

Our increased understanding of the associations between broadly measured emotion understanding and social behaviour for children in schools has implications for the related field of social and emotional learning (SEL). SEL interventions aim to develop social and emotional skills through explicit instruction in the context of learning environments that are safe, caring, well-managed, and participatory (Humphrey, 2013). Our finding that a lower level of broadly defined emotion understanding, as measured using AEI assessments, is linked to aggression supports the theory of change underpinning SEL (CASEL, 2007), and aligns well with the now substantial body of evidence that such interventions can produce meaningful reductions in externalising behaviour problems (Durlak, Weissberg, Dymnicki, Taylor, \& Schellinger, 2011; Sklad, Diekstra, De Ritter, Ben, \& Gravesteijn, 2012; Wigelsworth et al, 2016). However, there are also cautionary notes. Our findings support the notion that there is a shift from direct to indirect forms of aggression associated with high AEI. Instead of being viewed as problematic, this may simply be a natural developmental trend. Finally, the lack of a link between high AEI and prosocial behaviour in the current study appears to be incongruent with SEL theory. That is, those children better able to perceive, facilitate, understand, and manage their own and others' emotions did not necessarily apply those skills to engage in more positive social interactions. Such work highlights the need to consider the use of emotion understanding skill/emotion understanding self-efficacy (AEI/ESE) profiles that we discussed earlier.

\section{Conclusion}

The current study examined whether AEI was associated with social behaviour among children as observed over one school year. Using a broad measure of emotion 
understanding in late childhood, we showed that emotion understanding was linked to social processes in very specific ways. Our findings also highlighted the importance of examining gender and quadratic relationships. We are hopeful that this work will guide the design of future school-based interventions designed to increase the different skill sets of emotion understanding as defined by the AEI framework and proposed by the EUReKA model of emotion understanding. 


\section{References}

Altmann, J. (1974). Observational study of behaviour: sampling methods. Behaviour, 49, 227-266. doi: 10.1163/156853974x00534

Beck, L., Kumschick, I. R., Eid, M., \& Klann-Delius, G. (2012). Relationship between language competence and emotional competence in middle childhood. Emotion, 12, 503-514. doi: 10.1037/a0026320

Berg, B. L. \& Lune, H. (2004). Qualitative research methods for the social sciences (Vol. 5). Boston, MA: Pearson.

Björkqvist, K. (1994). Sex differences in physical, verbal, and indirect aggression: A review of recent research. Sex Roles, 30, 177-188. doi: 10.1007/bf01420988

Blatchford, P., Kutnick, P., Baines, E., \& Galton, M. (2003). Toward a social pedagogy of classroom group work. International Journal of Educational Research, 39, 153172. doi: 10.1016/s0883-0355(03)00078-8

Brackett, M. A., Mayer, J. D., \& Warner, R. M. (2004). Emotional intelligence and its relation to everyday behaviour. Personality and Individual Differences, 36, 13871402. doi: 10.1016/s0191-8869(03)00236-8

Brackett, M. A., Rivers, S. E., Shiffman, S., Lerner, N., \& Salovey, P. (2006). Relating emotional abilities to social functioning: A comparison of self-report and performance measures of emotional intelligence. Journal of Personality and Social Psychology, 91, 780-795. doi:10.1037/0022-3514.91.4.780

CASEL (2007). How evidence-based SEL programs work to produce greater student success in school and life. Chicago, IL: CASEL. 
Castro, V. L., Cheng, Y., Halberstadt, A. G., \& Grühn, D. (2016). EUReKA! A conceptual model of emotion understanding. Emotion Review, 8, 258-268. doi: $10.1177 / 1754073915580601$

Castro, V. L., Halberstadt, A. G., \& Garrett-Peters, P. (2016). A three-factor structure of emotion understanding in third-grade children. Social Development, 25, 602-622. doi:10.1111/sode. 12162

Cha, C. B., \& Nock, M. K. (2009). Emotional intelligence is a protective factor for suicidal behaviour. Journal of the American Academy of Child \& Adolescent Psychiatry, 48, 422-430. doi: 10.1097/chi.0b013e3181984f44

Charbonneau, D., \& Nicol, A. A. (2002). Emotional intelligence and prosocial behaviours in adolescents. Psychological Reports, 90, 361-370.

doi: $10.2466 / p r 0.2002 .90 .2 .361$

Ciarrochi, J. V., Chan, A. Y., \& Baigar, J. (2001). Measuring emotional intelligence in adolescents. Personality and Individual Differences, 31, 1105-1119. doi: $10.1016 / \mathrm{s} 0191-8869(00) 00207-5$

Ciarrochi, J. V., Chan, A. Y., \& Caputi, P. (2000). A critical evaluation of the emotional intelligence construct. Personality and Individual Differences, 28, 539-561. doi: $10.1016 / \mathrm{s} 0191-8869(99) 00119-1$

Clegg, J., Law, J., Rush, R., Peters, T. J., \& Roulstone, S. (2015). The contribution of early language development to children's emotional and behavioural functioning at 6 years: An analysis of data from the Children in Focus sample from the ALSPAC birth cohort. Journal of Child Psychology and Psychiatry, 56, 67-75. doi: 
$10.1111 /$ jcpp. 12281

Cohen, J., Cohen, P., West, S. G., \& Aiken, L. S. (2003). Applied multiple regression/correlation analysis for the behavioral sciences (3rd ed.). Mahawah, NJ: Lawrence Erlbaum.

Coplan, R. J., Gavinski-Molina, M. H., Lagacé-Séguin, D. G., \& Wichmann, C. (2001). When girls versus boys play alone: Non-social play and adjustment in kindergarten. Developmental Psychology, 37, 464-474. doi:10.1037//0012-1649.37.4.464

Crick, N. R., Ostrov, J. M., Burr, J. E., Cullerton-Sen, C., Jansen-Yeh, E., \& Ralston, P. (2006). A longitudinal study of relational and physical aggression in preschool. Journal of Applied Developmental Psychology, 27, 254-268. doi: 10.1016/j.appdev.2006.02.006

Crick, N. R., Ostrov, J. M., \& Kawabata, Y. (2007). Relational aggression and gender: An overview. In D. J. Flannery, I. Waldman, \& A. Vazsonyi (Eds.), The Cambridge handbook of violent behavior and aggression (pp. 243-258). Cambridge: Cambridge University Press. doi: 10.1017/cbo9780511816840.012

David, C. F., \& Kistner, J. A. (2000). Do positive self-perceptions have a 'dark side'? Examination of the link between perceptual bias and aggression. Journal of Abnormal Child Psychology, 28, 327-337. doi:10.1023/A:1005164925300

Davis, S. K., \& Humphrey, N. (2012). The influence of emotional intelligence (EI) on coping and mental health in adolescence: Divergent roles for trait and ability EI. Journal of Adolescence, 35, 1369-1379. doi:

10.1016/j.adolescence.2012.05.007

Department for Communities and Local Government. (2015, January). The english 
indices of deprivation. Retrieved from

https://www.gov.uk/government/uploads/system/uploads/attachment_data/file/465 791/English_Indices_of_Deprivation_2015_-_Statistical_Release.pdf

Department for Education. (2012, January). Schools, pupils, and their characteristics (SFR10/2012). Retrieved from https://www.gov.uk/government/uploads/system/uploads/attachment_data/file/219 260/sfr10-2012.pdf

Department for Education. (2013, January). Special educational needs in England (SFR 30/2013). Retrieved from https://www.gov.uk/government/uploads/system/uploads/attachment_data/file/225 699/SFR30-2013_Text.pdf

Diamantopoulou, S., Rydell, A., \& Henricsson, L. (2008). Can both low and high selfesteem be related to aggression in children? Social Development, 17, 682-698. doi: 10.1111/j.1467-9507.2007.00444.x

Duncan, S. C., Duncan, T. E., \& Strycker, L. A. (2006). Alcohol use from ages 9 to 16: A cohort-sequential latent growth model. Drug and Alcohol Dependence, 81, 7181. doi: 10.1016/j.drugalcdep.2005.06.001

Dunn, L., Dunn, M., Whetton, C., \& Burley, J. (1997). British Picture Vocabulary Scale. (BPVS-II) (2nd ed.). Windsor, Berks: NFER-Nelson.

Durlak, J. A., Weissberg, R. P., Dymnicki, A. B., Taylor, R. D., \& Schellinger, K. B. (2011). The impact of enhancing students' social and emotional learning: A metaanalysis of school-based universal interventions. Child Development, 82, 405-32. doi: /10.1111/j.1467-8624.2010.01564.x

Esturgó-Deu, M. E., \& Sala-Roca, J. (2010). Disruptive behaviour of students in primary education and emotional intelligence. Teaching and Teacher Education, 26, 830- 
837. doi: $10.1016 /$ j.tate.2009.10.020

García-Sancho, E., Salguero, J. M., \& Fernández-Berrocal, P. (2016). Angry rumination as a mediator of the relationship between ability emotional intelligence and various types of aggression. Personality and Individual Differences, 89, 143-147. doi: 10.1016/j.paid.2015.10.007

Gohm, C. L., Corser, G. C., \& Dalsky, D. J. (2005). Emotional intelligence under stress: Useful, unnecessary, or irrelevant? Personality and Individual Differences, 39, 1017-1028. doi: 10.1016/j.paid.2005.03.018

Hoglund, W. L. G., Lalonde, C. E., \& Leadbeater, B. J. (2008). Social-cognitive competence, peer rejection, and neglect, and behavioural and emotional problems in middle childhood. Social Development, 17, 528-553. doi: 10.1111/j.14679507.2007.00449.x.

Hubbard, J. A., Smithmyer, C. M., Ramsden, S. R., Parker, E. H., Flanagan, K. D., Dearing, K. F. \& Simons, R. F. (2002). Observational, physiological, and selfreport measures of children's anger: Relations to reactive versus proactive aggression. Child Development, 73, 1101-1118. doi: 10.1111/1467-8624.00460

Humphrey, N. (2013). Social and emotional learning: A critical appraisal. London: Sage. doi: $10.4135 / 9781446288603$

Hughes, J. N., Cavell, T. A., \& Grossman, P. A. (1997). A positive view of self: Risk or protection for aggressive children? Development and Psychopathology, 9, 75-94. doi: 10.1017/S0954579497001077

Lopes, P. N., Brackett, M. A., Nezlek, J. B., Schutz, A., Sellin, I., \& Salovey, P. (2004). Emotional intelligence and social interaction. Personality and Social Psychology Bulletin, 30, 1018 -1034. doi: 10.1177/0146167204264762

Lopes, P. N., Mestre, J. M., Guil, R., Kremenitzer, J. P., \& Salovey, P. (2012). The role 
of knowledge and skills for managing emotions in adaptation to school social behaviour and misconduct in the classroom. American Educational Research Journal, 49, 710-742. doi: 10.3102/0002831212443077

Lopes, P. N., Salovey, P., Côté, S., Beers, M., \& Petty, R. E. (2005). Emotion regulation abilities and the quality of social interaction. Emotion, 5, 113-118. doi: $10.1037 / 1528-3542.5 .1 .113$

MacNeil, B. M., \& Holden, R. R. (2006). Psychopathy and the detection of faking on selfreport inventories of personality. Personality and Individual Differences, 41, 641651. doi: 10.1016/j.paid.2006.03.004

Marlow, D., \& Crowne, D. P. (1961). Social desirability and response to perceived situational demands. Journal of Consulting Psychology, 25, 109-115. doi: $10.1037 / \mathrm{h} 0041627$

Mayer J. D., Caruso D. R., Salovey P. (2016). The ability model of emotional intelligence: principles and updates. Emotion Review, 8, 290-300. doi: $10.1177 / 1754073916639667$

Mayer, J. D., \& Salovey, P. (1993). The intelligence of emotional intelligence. Intelligence, 17, 433-442. doi: 10.1016/0160-2896(93)90010-3

Mayer, J. D. \& Salovey, P. (1997). What is emotional intelligence? In P. Salovey \& D. Sluyter (Eds.), Emotional development and emotional intelligence: Implications for educators (pp 3-34). New York, NY: Basic Books.

Mayer, J. D., Salovey, P. \& Caruso, D. R. (2005). Mayer-Salovey-Caruso Emotional Intelligence Test: Youth Version, Research Version 1.0. Toronto, Canada: MultiHealth Systems.

Mayer, J. D., Salovey, P., \& Caruso, D. R. (2008). Emotional intelligence: New ability or eclectic traits? American Psychologist, 63, 503-517. 
McQuade, J. D., Achufusi, A. K., Shoulberg, E. K., \& Murray-Close, D. (2014). Biased self-perceptions of social competence and engagement in physical and relational aggression: The moderating role of peer status and sex. Aggressive Behavior, 40, 512-525. doi: 10.1002/ab.21552

Pellegrini, A. D. (1996). Observing children in their natural worlds: A methodological primer. Mahwah, NJ: Erlbaum.

Petrides, K. V., Pita, R., \& Kokkinaki, F. (2007). The location of trait emotional intelligence in personality factor space. British Journal of Psychology, 98, 273-289. doi: $10.1348 / 000712606 \times 120618$

Qualter, P., Davis, S. K., Keefer' K. V., Parker, J. D. A., Saklofske, D. H., Wigelsworth' M., Simmons, N., \& Stough, C. (2018). Emotional competency in education: Core concepts and applications. British Journal of Educational Psychology Monograph Series II: Psychological aspects of education - current trends, 12, 51-79.

Qualter, P., Whiteley, H. E., Hutchinson, J. M., \& Pope, D. J., (2007). Supporting the development of Emotional Intelligence competencies to ease the transition from primary to high school. Educational Psychology in Practice, 23, 79-95. doi: $10.1080 / 02667360601154584$

Rivers, S. E., Brackett, M. A., Reyes, M. R., Mayer, J. D., Caruso, D. R., \& Salovey, P. (2012). Measuring emotional intelligence in early adolescence with the MSCEITYV psychometric properties and relationship with academic performance and psychosocial functioning. Journal of Psychoeducational Assessment, 30, 344-366. doi: $10.1177 / 0734282912449443$

Roberts, R. D., Schulze, R., \& MacCann, C. (2008). The measurement of emotional intelligence: A decade of progress? In G. J. Boyle, G. Matthews, \& D. H. Saklofske (Eds.), The Sage handbook of personality theory and assessment, Vol. 2 (pp 461- 
482). Thousand Oaks, CA: Sage Publications.

Rotenberg, K. J., Qualter, P., Holt, N., \& Harris, R., Barrett, L. \& Henzi, P. (2014). Interpersonal trust and playground behaviour. Journal of Abnormal Child Psychology, 42, 967-980. doi: 10.1007/s10802-013-9835-8

Salguero, J. M., Extremera, N., Cabello, R., \& Fernández-Berrocal, P. (2015). If you have high emotional intelligence (EI), you must trust in your abilities: The interaction effect of ability EI and perceived EI on depression in women. Journal of Psychoeducational Assessment, 33, 46-56. doi: 10.1177/0734282914550384

Salovey, P. \& Mayer, J. D. (1990). Emotional intelligence. Imagination, Cognition, and Personality, 9, 185-211. doi: 10.2190/dugg-p24e-52wk-6cdg

Sandstrom, M. J., \& Herlan, R. D. (2007). Threatened egotism or confirmed inadequacy? How children's perceptions of social status influence aggressive behavior toward peers. Journal of Social and Clinical Psychology, 26, 240-267. doi: 10.1521/jscp.2007.26.2.240

Saarni, C. (1999). The development of emotional competence. New York, NY: Guilford.

Saarni, C. (2007). The development of emotional competence: pathways for helping children to become emotionally intelligent. In R. Bar-On, J. G. Maree, \& M. J. Elias (Eds.), Educating people to be emotionally intelligent (pp 15-35). Westport, CT: Praeger Publishers/Greenwood Publishing Group.

Sheldon, O. J., Dunning, D., \& Ames, D. R. (2014). Emotionally unskilled, unaware, and uninterested in learning more: Reactions to feedback about deficits in emotional intelligence. Journal of Applied Psychology, 99, 125-137. doi: 10.1037/a0034138

Sklad, M., Diekstra, R., De Ritter, M., Ben, J., \& Gravesteijn, C. (2012). Effectiveness of school-based universal social, emotional, and behavioral programs: Do they enhance students' development in the area of skills, behavior and adjustment? 
Psychology in the Schools, 49, 892-909. doi: 10.1002/pits.21641

Trentacosta, C. J., \& Fine, S. E. (2010). Emotion knowledge, social competence, and behaviour problems in childhood and adolescence: A meta-analytic review. Social Development, 19, 1-29. doi: 10.1111/j.1467-9507.2009.00543.x.

Vaillancourt T. (2013). Do human females use indirect aggression as an intrasexual competition strategy? Philosophical Transactions of the Royal Society B: Biological Sciences 368, 20130080. doi:10.1098/ rstb.2013.0080

Van de Mortel, T. F. (2008). Faking it: Social desirability response bias in self-report research. Australian Journal of Advanced Nursing, 25, 40-48.

Veiga, G., Ketelaar, L., De Leng, W., Cachucho, R., Kok, J. N., Knobbe, A., Neto, C. \& Rieffe, C. (2017). Alone at the playground. European Journal of Developmental Psychology, 14, 44-61, doi: 10.1080/17405629.2016.1145111

Voulgaridou, I., \& Kokkinos, C.M. (2015). Relational aggression in adolescents: A review of theoretical and empirical research. Aggression and Violent Behavior, 23, 87-97. doi: 10.1016/j.avb.2015.05.006

Wigelsworth, M., Lendrum, A., Oldfield, J., Scott, A., Ten-Bokkel, I., Tate, K., \& Emery, C. (2016). The impact of trial stage, developer involvement and international transferability on the outcomes of universal social and emotional learning outcomes: A meta-analysis. Cambridge Journal of Education, 46, 347-376. doi: $10.1080 / 0305764 x .2016 .1195791$ 
Table 1. Means and Standard Deviations for Study Variables.

\begin{tabular}{|c|c|c|c|c|}
\hline \multirow[t]{2}{*}{ Study Variable } & \multirow[t]{2}{*}{ Means } & \multirow[t]{2}{*}{ Standard Deviation } & \multicolumn{2}{|c|}{ Range } \\
\hline & & & $\min$ & $\max$ \\
\hline AEI & 98.060 & 12.879 & 60.282 & 120.209 \\
\hline Verbal Ability & 101.461 & 14.666 & 67.000 & 134.000 \\
\hline Peer Acceptance/Rejection $\gamma$ & .346 & .369 & 0.000 & 1.448 \\
\hline Prosocial Behaviour & 71.911 & 12.661 & 21.984 & 93.142 \\
\hline Playing Alone & 1.004 & 2.089 & 0.000 & 14.539 \\
\hline Alone, Watching Peers & 2.079 & 2.630 & 0.000 & 12.174 \\
\hline Passivity & 17.019 & 9.637 & 1.461 & 40.321 \\
\hline Direct Aggression & .680 & .892 & 0.000 & 5.052 \\
\hline Social Exclusion ${ }^{\gamma}$ & .612 & 1.181 & 0.000 & 6.149 \\
\hline Distress & 2.161 & 5.330 & 0.000 & 34.708 \\
\hline
\end{tabular}

Note: ${ }^{\gamma}$ Peer rejection $=$ target child rejected by other(s) when they attempted interaction when they were alone; Social exclusion refers to situations where the target child ignores attempts to interact from peers whether that peer is involved in the larger group interaction or has been alone. Behaviours are noted here as the $\%$ of all behaviour observed; $4.19 \%$ of the observed behaviour was categorized as uncodable. 
Table 2. Summary of the Hierarchical Regression Analysis for Peer Acceptance/Rejection and Prosocial Behaviour

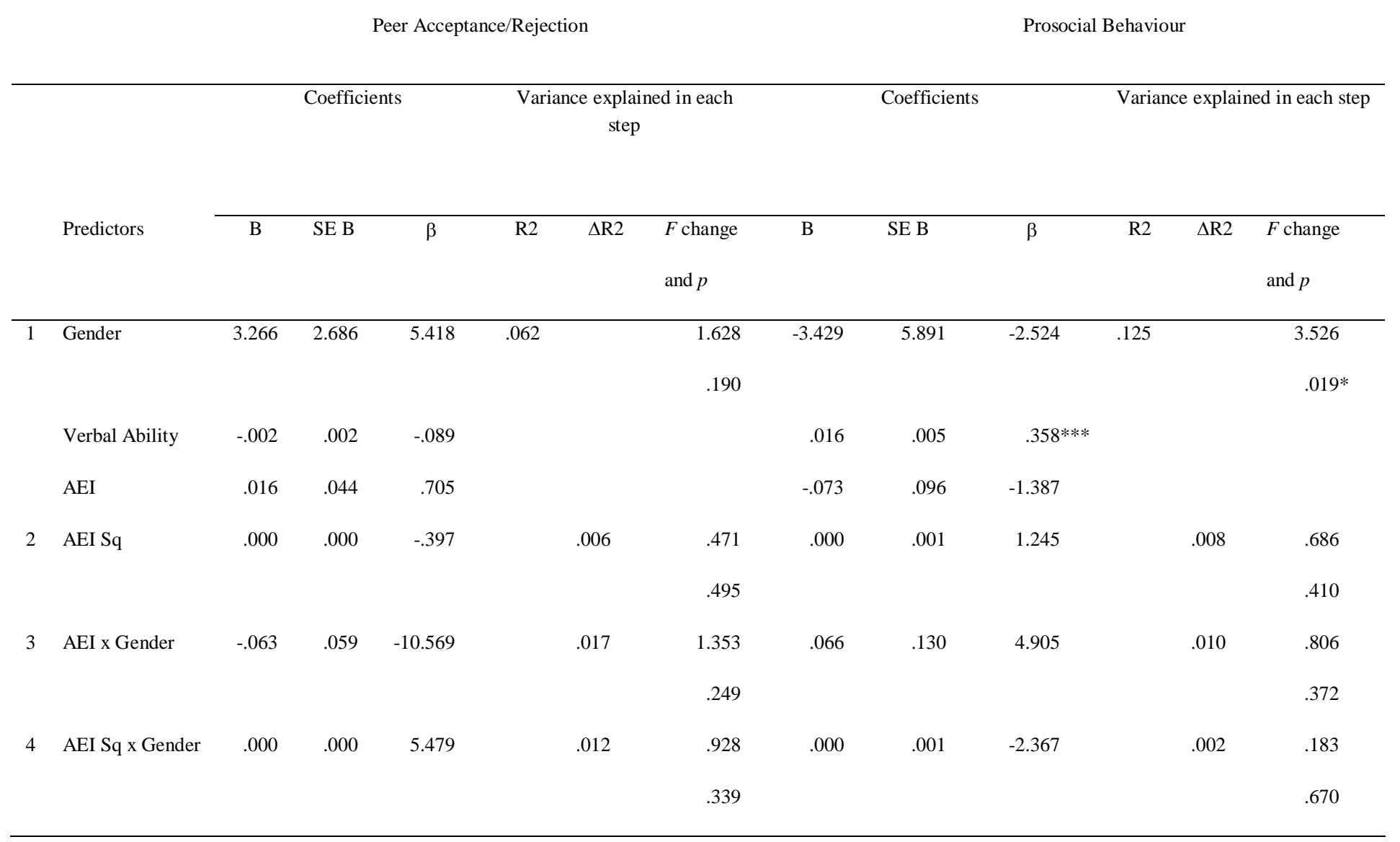

Notes. Table includes coefficients from the final step of the model. $* p<.05, * * * p<.001$. AEI $=$ Ability Emotional Intelligence;

AEI Sq = Ability Emotional Intelligence Squared. AEI Sq in the HRAs is the AEI x AEI and serves as a test for a quadratic relation (Cohen et al. 2003).

Gender was dummy coded $(0=$ female and $1=$ male $)$ 
Table 3. Summary of the Hierarchical Regression Analysis for Playing Alone, Alone but Watching Peers, and Passivity during Interaction.

\begin{tabular}{|c|c|c|c|c|c|c|c|c|c|c|c|c|c|c|c|c|c|c|c|}
\hline & \multirow[b]{3}{*}{ Predictors } & \multicolumn{6}{|c|}{ Playing alone } & \multicolumn{7}{|c|}{ Alone, watching others } & \multicolumn{5}{|c|}{ Passivity during interaction } \\
\hline & & \multicolumn{3}{|c|}{ Coefficients } & \multicolumn{3}{|c|}{$\begin{array}{c}\text { Variance explained in } \\
\text { each step }\end{array}$} & \multicolumn{3}{|c|}{ Coefficients } & \multicolumn{3}{|c|}{$\begin{array}{l}\text { Variance explained in } \\
\text { each step }\end{array}$} & \multicolumn{3}{|c|}{ Coefficients } & \multicolumn{3}{|c|}{$\begin{array}{l}\text { Variance explained in eacl } \\
\text { step }\end{array}$} \\
\hline & & $\mathrm{B}$ & SE B & $\beta$ & R2 & $\Delta \mathrm{R} 2$ & $\begin{array}{l}F \text { change } \\
\text { and } p\end{array}$ & $\mathrm{~B}$ & SE B & $\beta$ & $\mathrm{R} 2$ & $\Delta \mathrm{R} 2$ & $\begin{array}{l}F \\
\text { change } \\
\text { and } p\end{array}$ & $\mathrm{~B}$ & SE B & $\beta$ & $\mathrm{R} 2$ & $\Delta \mathrm{R} 2$ & $\begin{array}{l}F \text { change } \\
\text { and } p\end{array}$ \\
\hline \multirow[t]{3}{*}{1} & Gender & 1.388 & 3.465 & 1.740 & .006 & & $\begin{array}{l}.143 \\
.934\end{array}$ & 17.672 & 7.616 & $9.881 * *$ & .090 & & $\begin{array}{c}2.432 \\
.072 \dagger\end{array}$ & 19.617 & 10.776 & $8.269^{*}$ & .006 & & $\begin{array}{l}.139 \\
.937\end{array}$ \\
\hline & $\begin{array}{l}\text { Verbal } \\
\text { Ability }\end{array}$ & .001 & .003 & .037 & & & & .011 & .007 & .190 & & & & -.008 & .010 & -.102 & & & \\
\hline & AEI & .005 & .057 & .158 & & & & .105 & .124 & 1.516 & & & & .357 & .176 & $3.897^{* *}$ & & & \\
\hline \multirow[t]{2}{*}{2} & AEI Sq & .000 & .000 & .325 & & .005 & .383 & -.001 & .001 & -1.456 & & .011 & .923 & -.002 & .001 & $-3.895^{*}$ & & .012 & .903 \\
\hline & & & & & & & .538 & & & & & & .340 & & & & & & .345 \\
\hline \multirow[t]{2}{*}{3} & $\begin{array}{l}\text { AEI } x \\
\text { Gender }\end{array}$ & -.002 & .076 & $-.262 * *$ & & .129 & 10.836 & -.359 & .168 & $-20.228 * *$ & & .028 & 2.317 & -.434 & .237 & $-18.458^{*}$ & & .001 & .042 \\
\hline & & & & & & & .002 & & & & & & .132 & & & & & & .838 \\
\hline \multirow[t]{2}{*}{4} & $\begin{array}{l}\text { AEI Sq x } \\
\text { Gender }\end{array}$ & .000 & .000 & -1.549 & & .001 & .078 & .002 & .001 & $10.880^{* * *}$ & & .047 & 4.012 & .002 & .001 & $10.537 *$ & & .044 & $\begin{array}{l}3.306 \\
.073 \dagger\end{array}$ \\
\hline & & & & & & & .781 & & & & & & $.049 *$ & & & & & & \\
\hline
\end{tabular}

Notes. Table includes coefficients from the final step of the model. $* * p<.01, *<.05 ; \dagger p<.08$; AEI $=$ Ability Emotional Intelligence. AEI Sq $=$ Ability Emotional Intelligence Squared. AEI Sq in the HRAs is the AEI

$x$ AEI and serves as a test for a quadratic relation (Cohen et al. 2003). Gender was dummy coded ( $0=$ female and $1=$ male). 
Table 4. Summary of the Hierarchical Regression Analysis for Physical Aggression, Social Exclusion, and Distress.

\begin{tabular}{|c|c|c|c|c|c|c|c|c|c|c|c|c|c|c|c|c|c|c|c|}
\hline & \multirow[b]{3}{*}{ Predictors } & \multicolumn{6}{|c|}{ Physical Aggression } & \multicolumn{7}{|c|}{ Social Exclusion } & \multicolumn{5}{|c|}{ Distress } \\
\hline & & \multicolumn{3}{|c|}{ Coefficients } & \multicolumn{3}{|c|}{$\begin{array}{l}\text { Variance explained in } \\
\text { each step }\end{array}$} & \multicolumn{3}{|c|}{ Coefficients } & \multicolumn{3}{|c|}{$\begin{array}{l}\text { Variance explained in each } \\
\text { step }\end{array}$} & \multicolumn{3}{|c|}{ Coefficients } & \multicolumn{3}{|c|}{$\begin{array}{c}\text { Variance explained in each } \\
\text { step }\end{array}$} \\
\hline & & B & SE B & $\beta$ & R2 & $\Delta \mathrm{R} 2$ & $\begin{array}{l}F \text { change } \\
\text { and } p\end{array}$ & B & SE B & $\beta$ & $\mathrm{R} 2$ & $\Delta \mathrm{R} 2$ & $\begin{array}{l}F \text { change } \\
\text { and } p\end{array}$ & B & SE B & $\beta$ & $\mathrm{R} 2$ & $\Delta \mathrm{R} 2$ & $\begin{array}{l}F \text { change } \\
\text { and } p\end{array}$ \\
\hline 1 & Gender & -5.889 & 4.054 & -6.120 & .136 & & $\begin{array}{l}.874 \\
.012 *\end{array}$ & 2.876 & 3.021 & -4.155 & .045 & & $\begin{array}{r}1.172 \\
.326\end{array}$ & -28.264 & 106.472 & $-1.132 * * *$ & .173 & & $\begin{array}{l}4.942 \\
.004 * *\end{array}$ \\
\hline & $\begin{array}{l}\text { Verbal } \\
\text { Ability }\end{array}$ & -.012 & .004 & $.355 * * *$ & & & & -.004 & .003 & -.184 & & & & .134 & .096 & .161 & & & \\
\hline & AEI & -.108 & .066 & -2.908 & & & & -.115 & .049 & $-4.289 *$ & & & & .106 & 1.751 & .112 & & & \\
\hline 2 & $\mathrm{AEI} \mathrm{Sq}$ & .001 & .000 & 3.000 & & .000 & $\begin{array}{l}.023 \\
.879\end{array}$ & .001 & .000 & $4.460^{*}$ & & .071 & $\begin{array}{l}5.853 \\
.018^{*}\end{array}$ & .000 & .010 & .073 & & .005 & $\begin{array}{l}.397 \\
.531\end{array}$ \\
\hline 3 & $\begin{array}{l}\text { AEI } x \\
\text { Gender }\end{array}$ & .149 & .089 & 15.607 & & .020 & $\begin{array}{r}1.731 \\
.192\end{array}$ & .067 & .067 & 9.764 & & .004 & $\begin{array}{l}.301 \\
.585\end{array}$ & .681 & 2.351 & 2.751 & & .012 & $\begin{array}{r}1.033 \\
.313\end{array}$ \\
\hline 4 & $\begin{array}{l}\text { AEI Sq x } \\
\text { Gender }\end{array}$ & -.001 & .000 & $-9.678^{*}$ & & .037 & $\begin{array}{l}3.243 \\
.076 \dagger\end{array}$ & .000 & .000 & -5.921 & & .014 & $\begin{array}{r}1.130 \\
.291\end{array}$ & -.005 & .013 & -2.106 & & .002 & $\begin{array}{l}.148 \\
.702\end{array}$ \\
\hline
\end{tabular}

Notes. Table includes coefficients from the final step of the model; $* * * p=.001, * * p<.01, * p<.05 ; \dagger=p<.08$; AEI $=$ Ability Emotional Intelligence. AEI Sq $=$ Ability Emotional Intelligence Squared. AEI Sq in the

HRAs is the AEI $x$ AEI and serves as a test for a quadratic relation (Cohen et al. 2003). Gender was dummy coded $(0=$ female and $1=$ male). 
List of Captions for Ability Emotional Intelligence and Children's Behaviour in the Playground.

Figure 1. Linear and Quadratic Relations for Alone, but Watching Others for Boys. Figure 2. Linear and Quadratic Relations for Physical Aggression for Girls. Figure 3. Linear and Quadratic Relations for Passivity during Interaction for Girls. Figure 4. Linear and Quadratic Relations for Social Exclusion for Full Sample. 
Figure 1. Linear and Quadratic Relations for Alone, but Watching Others for Boys.

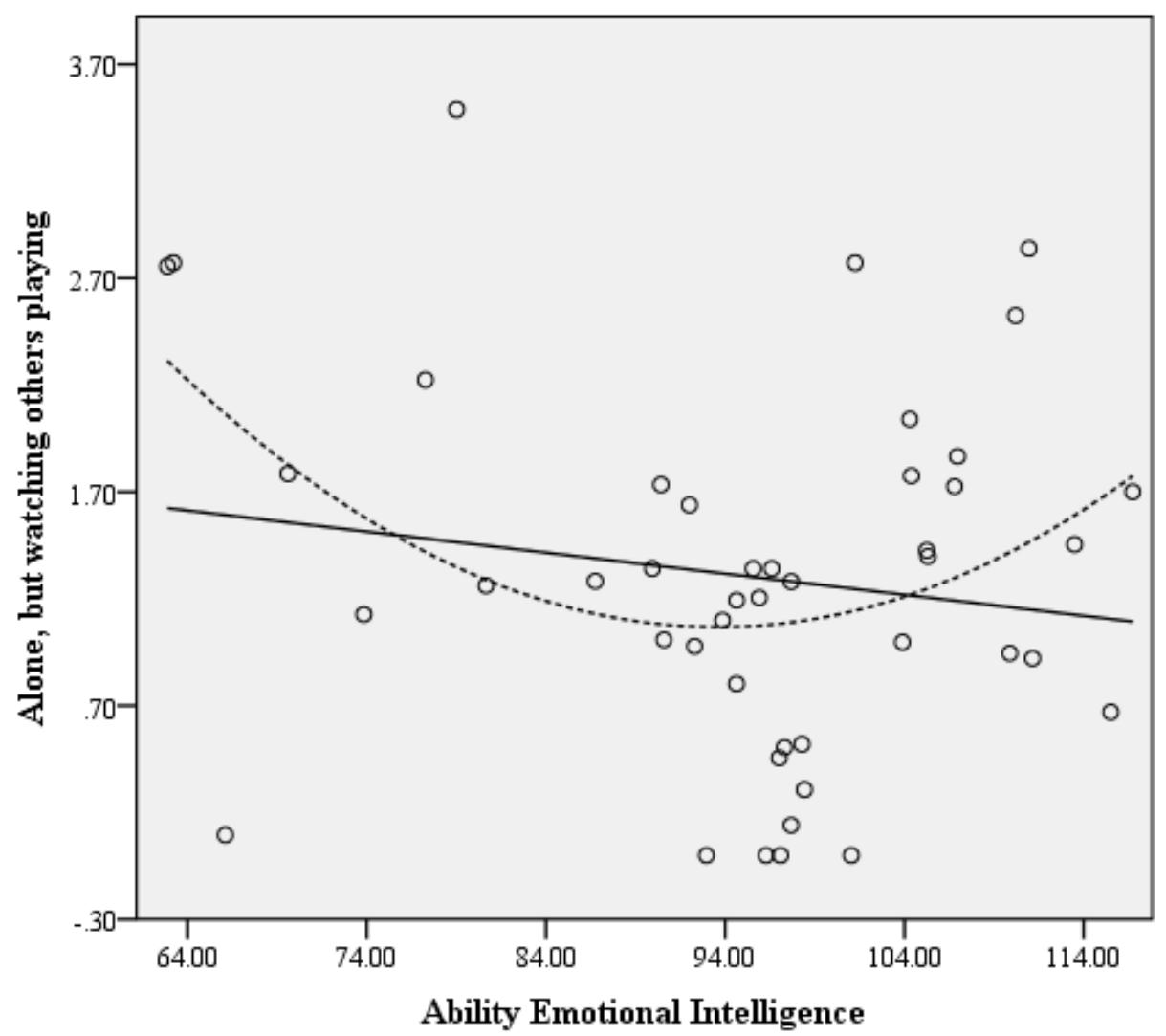

Notes: Behaviour noted in the figure is the transformed behavioural data. The quadratic regression term is significant, suggesting that boys high and low in AEI are more likely to watch others playing when alone than boys in the mid-range of AEI scores. 
Figure 2. Linear and Quadratic Relations for Physical Aggression for Girls.

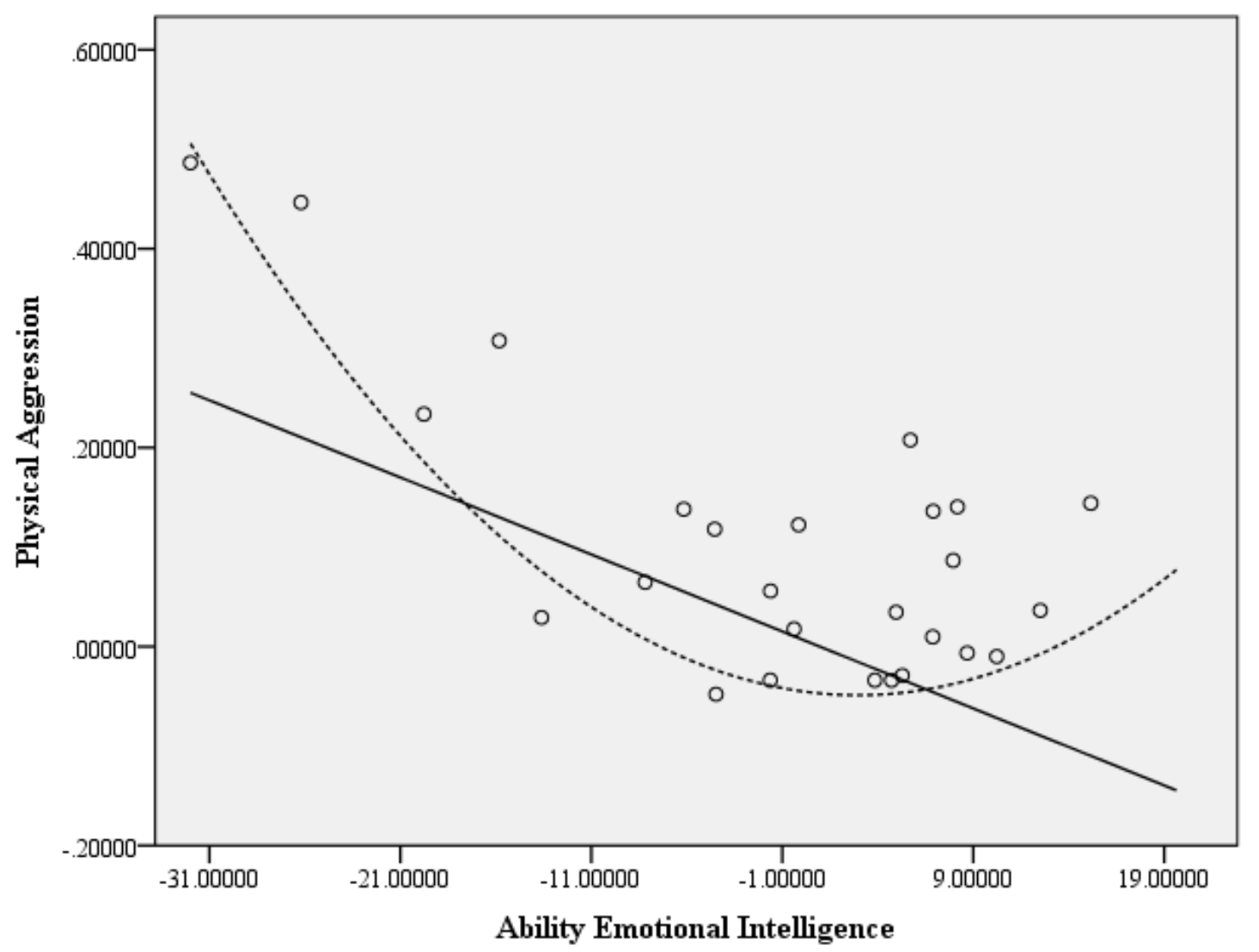

Notes: Because we showed that verbal ability was a significant predictor of observed physical aggression, and was also a significant correlate of AEI $(\mathrm{r}=0.29, \mathrm{n}=78, \mathrm{p}=$ 0.010), we regressed it onto both observed physical behaviour and AEI to create residuals that are used to create this figure. The quadratic regression term is significant, suggesting that girls low in AEI are significantly more likely to physically aggress against their peers than girls in the mid or high range of AEI. 
Figure 3. Linear and Quadratic Relations for Passivity during Interaction for Girls.

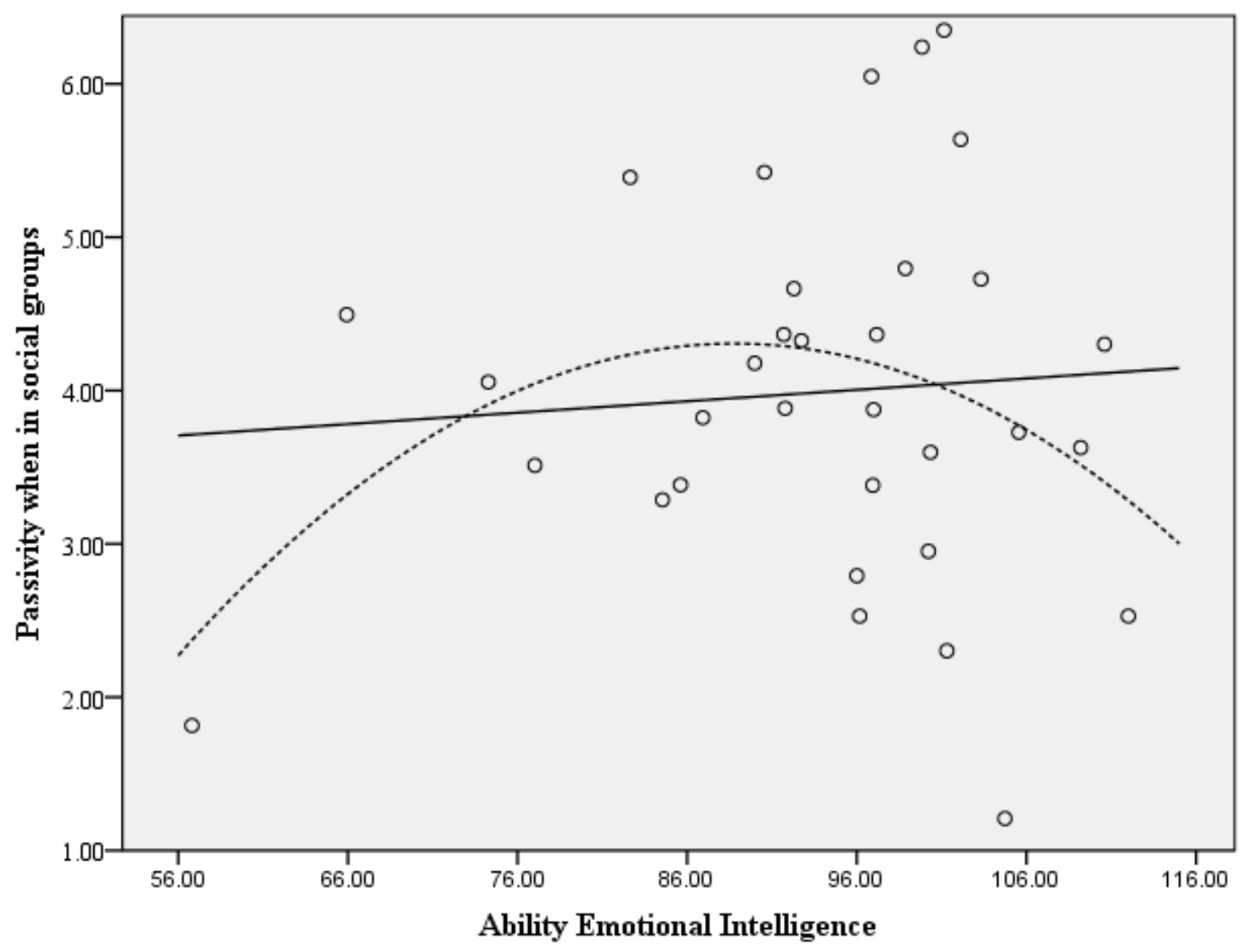

Notes: Behaviour noted in the figure is the transformed behavioural data. The quadratic regression term is significant, suggesting that girls high and low in AEI were more likely to be passive during interaction than their same-sex peers scoring in the mid-range of AEI. 
Figure 4. Linear and Quadratic Relations for Social Exclusion for Full Sample

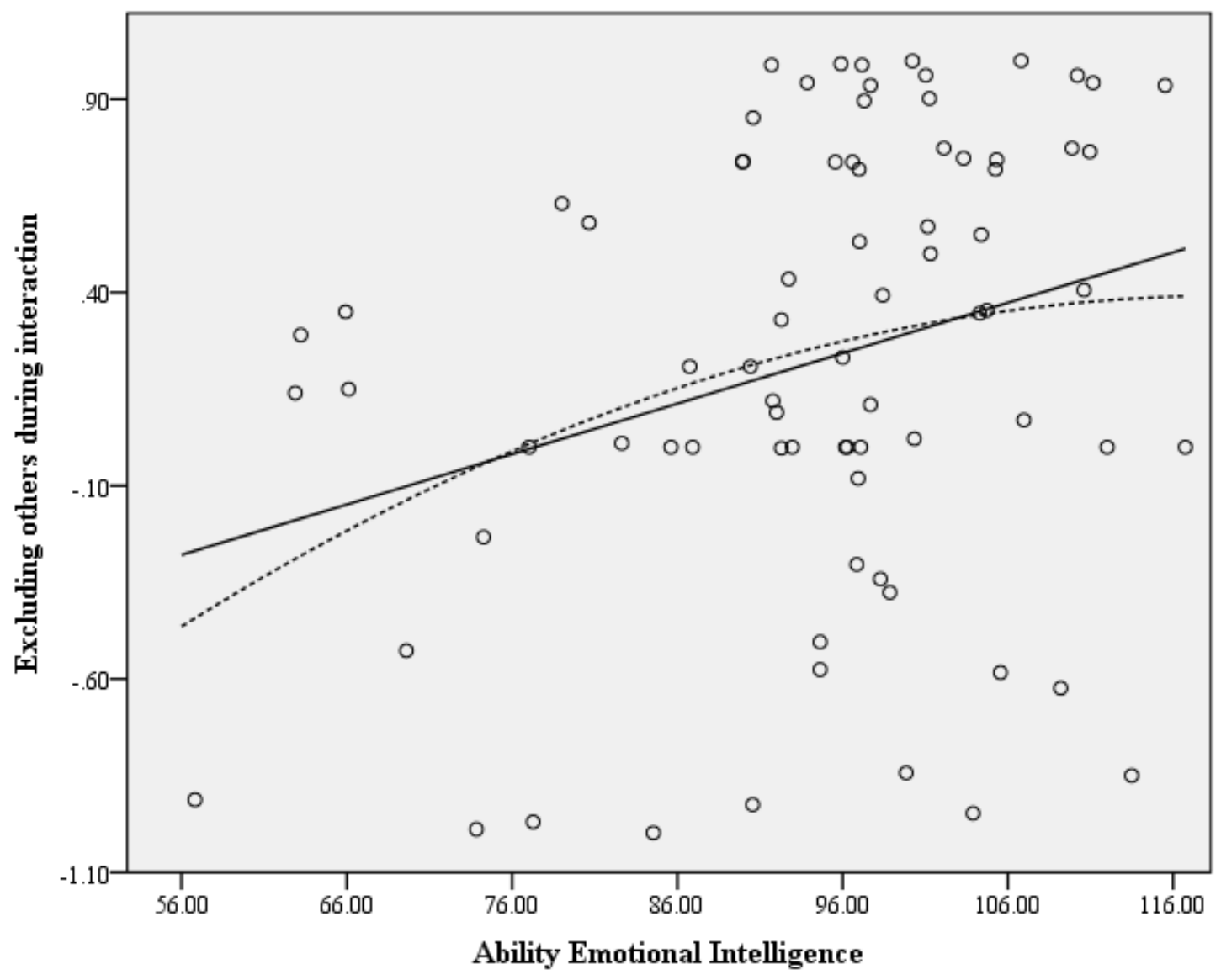

Notes: Behaviour noted in the figure is the transformed behavioural data. The quadratic regression term is significant, with children high in AEI and those in the mid range of EI engaged in more indirect aggression than those low in AEI. 